OPEN ACCESS

Edited by:

Khawar Jabran,

Nigde Ömer Halisdemir

University, Turkey

Reviewed by:

Agnieszka Synowiec,

University of Agriculture in

Krakow, Poland

Nadeem labal,

The University of

Queensland, Australia

*Correspondence:

Karla L. Gage

kgage@siu.edu

${ }^{\dagger}$ These authors have contributed equally to this work

Specialty section:

This article was submitted to Weed Management,

a section of the journal

Frontiers in Agronomy

Received: 09 December 2021

Accepted: 12 January 2022

Published: 04 February 2022

Citation:

Shikanai A and Gage KL (2022)

Allelopathic Potential of Hemp:

Implications for Integrated Weed

Management

Front. Agron. 4:832471

doi: 10.3389/fagro.2022.832471

\section{Allelopathic Potential of Hemp: Implications for Integrated Weed Management}

\author{
Avery Shikanai ${ }^{1 \dagger}$ and Karla L. Gage ${ }^{1,2,3 * \dagger}$ \\ ${ }^{1}$ School of Biological Sciences, Southern Illinois University Carbondale, Carbondale, IL, United States, ${ }^{2}$ School of \\ Agricultural Sciences, Southern Illinois University Carbondale, Carbondale, IL, United States, ${ }^{3}$ Cannabis Science Center, \\ Southern Illinois University Carbondale, Carbondale, IL, United States
}

Evolved resistance to herbicides necessitates alternative weed control strategies. Allelopathic crops show promise as an alternative to exogenous herbicides and could be used to reduce establishment, growth, and reproduction of weeds. Individual cannabinoids and terpenes found in hemp (Cannabis sativa L.) show allelopathic potential, but allelopathic effects of plant residue have not been characterized. A laboratory assay found that crude, acetone-soluble hemp extracts diluted to $2.5 \mathrm{mg}$ $\mathrm{mL}^{-1}$ reduced the germination of a bioindicator species. However, tested concentrations below $2.5 \mathrm{mg} \mathrm{mL}^{-1}$ were not more effective than the no-extract control treatment at reducing germination. A greenhouse study found that soil-incorporated hemp residue was not more effective than a maize (Zea mays L.) residue treatment comparison in reducing plant growth. However, a simulated chaff line experiment in the greenhouse showed that the equivalent of $378 \mathrm{~g} \mathrm{~m}^{-2}$ hemp residue on the soil surface can effectively reduce and delay the germination of waterhemp [Amaranthus tuberculatus (Moq.) Sauer] in comparison to bare-soil, or a maize residue treatment comparison. Together, these results show that incorporated hemp residue will likely not be an effective weed control practice. However, chaff lining hemp residue may be an effective practice for the control of certain weeds and warrants further research in a field setting.

Keywords: Amaranthus tuberculatus, Cannabis sativa, cannabinoids, cannabidiol, residue, terpene, chaff lining, CBD

\section{INTRODUCTION}

Hemp (Cannabis sativa L.) produces an unusual quantity and diversity of secondary metabolites, chemicals not directly related to normal growth and development. The most abundant secondary metabolites of hemp are terpenes and cannabinoids. Terpenes are derived from 5-carbon precursors, isopentenyl diphosphate, and dimethylallyl diphosphate, which are modified and joined to form mono-, di-, or sesquiterpenes (Chen et al., 2011) and stored in Cannabis glandular trichomes that cover leaves and pistillate bracts (Livingston et al., 2020). Glandular trichomes of Cannabis typically accumulate tetrahydrocannabinolic acid (THCa), cannabidiolic acid (CBDa), or a mixture of both (Toth et al., 2020). Cannabis high in THCa and its derivative, tetrahydrocannabinol (THC) is valued for its psychotropic properties and is referred to as marijuana. Cannabis low in THCa and THC is known as hemp, typically accumulating CBDa and its derivative, cannabidiol (CBD). Hemp is receiving renewed interest for its versatility, producing fiber, seed, and CBD, which has promising medical applications (Schluttenhofer and Yuan, 2017). 
The abundance and phytotoxicity of hemp terpenes and cannabinoids suggest that these secondary metabolites could act as allelochemicals. Individual terpenes are phytotoxic at low concentrations (Abrahim et al., 2000; De Martino et al., 2010), and extracted terpene mixtures from hemp can inhibit the germination and growth of seedlings in laboratory conditions (Agnieszka et al., 2016). Additionally, cannabinoids cause cell death in plant tissue culture (Sirikantaramas et al., 2005). Substantial energy and carbon is devoted to cannabinoid biosynthesis; leaves and flowers are up to 6 and $20 \%$ cannabinoid, respectively (Pacifico et al., 2008) and unpollinated pistillate flowers are up to $20 \%$ cannabinoid by dry weight (Fischedick et al., 2010). The abundance and phytotoxicity of hemp secondary metabolites led us to ask if these chemicals could be allelopathic, defined as causing physiological inhibition of other plants through chemical release (Inderjit et al., 2005; Duke, 2015). Allelopathy of hemp was mentioned as early as 1970 (Haney and Bazzaz, 1970) and has a plausible mechanistic basis but has not been rigorously tested. Little is known about the effects of both cannabinoids and terpenes on plant performance. Holistic study of potential allelochemicals is necessary, as interactions between metabolites can to amplify phytotoxic effects (Duke, 2015). Moreover, semi-realistic studies using whole-plant material and soil are needed to determine if hemp can be allelopathic in field conditions.

Incorporating hemp into crop rotations could be leveraged in service of sustainable, integrated weed management. Recurrent evolution of herbicide-resistant weeds in the face of strong selection has rendered many herbicides ineffective (Tranel et al., 2011). Furthermore, limited development of novel herbicides suggests that reliance on a decreasing number of effective herbicides will not be a sustainable weed management tactic (Duke, 2012). However, crops can be successfully and profitably produced with limited herbicide input in agricultural systems that incorporate multiple weed-control tactics (Westerman et al., 2005; Davis et al., 2012). Preliminary reports suggest that once established, hemp stands are competitive and can effectively suppress weeds (Sandler and Gibson, 2019). The potential competitive ability of hemp and weed-management benefits of crop rotation (Liebman and Dyck, 1993) highlights the potential role of hemp in an integrated weed management program.

In addition to growing competitive crops in rotation, allelopathic crops have the potential to reduce herbicide costs and off-target impacts (Relyea, 2009; Almberg et al., 2018; Bish et al., 2019). This potential is gradually being realized, as allelopathic cover crops such as cereal rye (Secale cereale L.) (Tabaglio et al., 2013) and red clover (Trifolium pratense L.) (Liebman and Sundberg, 2006) can successfully suppress weeds. Furthermore, cash crops with allelopathic potential include rice (Oryza sativa L.), wheat (Triticum aestivum L.), sorghum [Sorghum biccolor (L.) Moench.], and sunflower (Helianthus annuus L.), highlighting opportunities for integrated weed management (Jabran et al., 2015). However, little is known about any role of allelochemicals in hemp-weed interactions.

Management of allelopathic crop residue (Kruidhof et al., 2009) could potentially be paired with a harvest weed seed destruct method such as chaff lining for enhanced weed control (Walsh et al., 2018). Chaff lining is a practice that funnels chaff and weed seeds exiting combine harvesters into a narrow band, burying weed seeds within a layer of mulch. Chaff lining is a widely adopted practice in Australian grain production (Walsh et al., 2018), under the premise that weed seeds have limited access to safe-sites, reducing the effective size of the seedbank (Davis, 2006; Gallandt, 2006). Walsh et al. (2021) found that relatively high levels of chaff are needed to suppress emergence, indicating that weeds emerging from chaff lines could compete with subsequent crops and replenish seed banks if not controlled. However, potentially allelopathic hemp residue could integrate allelopathic control with physical weed control benefits of chaff lining.

Therefore, the overall objective of the present study was to determine the allelopathic potential of hemp residue extracts and residue in three experiments. The individual objectives of each study were to: (1) quantify the phytotoxicity of cannabinoid and terpene extracts on the germination of a bioindicator species in the laboratory, (2) quantify the phytotoxicity of hemp residue when incorporated into greenhouse soil by measuring plant growth of three weed and three crop species, and (3) quantify the phytotoxicity of hemp residue placed on the soil surface in a simulated, greenhouse chaff line experiment by measuring weed seed germination.

\section{MATERIALS AND METHODS}

\section{Laboratory Extract Experiment}

A growth chamber experiment was conducted to assay the phytotoxicity of hemp extracts on a bioindicator, Brassica napus L. ssp. pabularia 'Red Russian'. Rapid, synchronous germination makes $B$. napus an ideal bioindicator species (Koitabashi et al., 1997). Terpenes and cannabinoids were extracted by sonicating dried, unpollinated hemp flowers and leaves of hemp accession 21 Mother PH4 in acetone. Then, acetone was removed by rotary evaporation at $60^{\circ} \mathrm{C}$. Rotary evaporation at low temperatures is expected to preserve heat labile acidic cannabinoids (Wang et al., 2016), and retain semivolatile monoterpenes and sesquiterpenes. The crude extract was emulsified in deionized water using polysorbate-20 and then diluted to yield the following concentrations of emulsified hemp extract: $0.005,0.01,0.1,0.5,1,2.5$, and $5 \mathrm{mg} \mathrm{mL}^{-1}$. All emulsions were adjusted to contain $5 \mathrm{mg} \mathrm{mL}^{-1}$ polysorbate-20. These treatments were compared to a water control containing $5 \mathrm{mg} \mathrm{mL}^{-1}$ polysorbate- 20 .

A $2 \mathrm{~mL}$ aliquot of either a diluted extract or control solution was added to $100 \mathrm{~mm}$ petri plates lined with filter paper. Then, 20 surface-sterilized $B$. napus seeds were added to petri plates and then sealed with allpurpose laboratory film. Brassica napus seeds were surface sterilized by immersion in a $7 \% \quad \mathrm{v}: \mathrm{v}$ sodium hypochlorite solution for $10 \mathrm{~min}$ and then rinsed thoroughly with water.

The experiment was a randomized block design with 10 replicates of each treatment within each block. The experimental unit consisted of one petri plate containing 20 seeds. There were two blocks consisting of a single growth chamber at different times. Plates were randomly arranged inside a growth chamber under constant fluorescent light set at $24^{\circ} \mathrm{C}$ and incubated for 
$115 \mathrm{~h}$. After incubation, the number of seeds that germinated per plate were recorded. A seed was considered to have germinated if the radicle was visible.

\section{Greenhouse Experiments}

To test potential allelopathic effects of hemp in more realistic environments, two greenhouse experiments were conducted to examine the effects of hemp residue on the germination and growth of plants common in agricultural fields. Both experiments were conducted utilizing a pasteurized 1:1 mixture of sand to silt loam soil ( $22 \%$ sand, $58 \%$ silt, $20 \%$ clay, $2.5 \%$ organic matter, $\mathrm{pH}$ 6.8). Hemp and maize residues were finely ground to a similar consistency. Hemp residue used in both experiments consisted of dried, finely ground leaves and bracts taken from approximately the uppermost $30 \mathrm{~cm}$ of 21 Mother PH4 hemp plants. Leaves and bracts from the uppermost $30 \mathrm{~cm}$ represents the tissue likely to be expelled by combine harvesters during grain harvest. While the hemp accession 21 Mother PH4 is not used for grain production, it produces only slightly higher $\mathrm{CBD} \%$ by weight than some multipurpose fiber, grain, and $\mathrm{CBD}$ accessions, such as Boax marketed as producing up to $12 \%$ CBD (Colorado Breeders Depot, Canon City, CO, USA). Maize residue consisted of dried, finely ground leaves and stems collected after harvest. Maize residue was collected from a field without late-season or persistent herbicide applications. A maize residue treatment comparison (control) was used to account for the physical effect of residue alone and allows comparison to the residue interactions of a common rotational crop. Maize residue lacks cannabinoids; but, like many other plants, maize may emit terpenes in response to herbivory (Köllner et al., 2004).

\section{Growth in Residue Experiment}

The growth of six species was evaluated in the greenhouse in $11.5 \times 11.5 \mathrm{~cm}$ plastic pots filled with either soil, soil + hemp residue, or soil + maize residue. The soil treatment consisted of $500 \mathrm{~g}$ of soil. The soil + hemp treatment consisted of $5 \mathrm{~g}$ of dried, ground hemp residue thoroughly mixed with $495 \mathrm{~g}$ of soil. The soil + maize treatment consisted of $5 \mathrm{~g}$ of dried, maize residue thoroughly mixed with $495 \mathrm{~g}$ of soil. Three weed species (Amaranthus tuberculatus [Moq.] Sauer, Setaria pumila [Poir.] Roem. and Schult, and Abutilon theophrasti Medik.) and three crop species (Zea mays L., Cannabis sativa, and Glycine max [L.] Merr.) were assessed in response to the soil, soil + hemp, or soil + maize treatments.

Each species by treatment combination was replicated 10 times over two iterations (runs) of the experiment. Pots were arranged in a randomized complete block design with five replicates per run. The greenhouse was unshaded and highpressure sodium lights provided supplemental lighting at 250 $\mu \mathrm{mol} \mathrm{m}{ }^{-2} \mathrm{~s}^{-1}$ for $16 \mathrm{~h}$ each day. Five seeds of a selected species were sown just below the soil surface. Pots were watered every 23 days to maintain adequate moisture for growth. Ten days after planting, each pot was thinned to one plant, retaining the oldest surviving seedling.

Plant length (height) was measured 14, 21, and 28 days after plantings as the distance from the soil surface to the highest extending leaf. For grass species, tiller lengths to the furthest extending leaf tip were summed to determine total plant length. Above-ground biomass was harvested 28 days after planting and dried to constant weight at $60^{\circ} \mathrm{C}$ in a forced-air oven before weighing. In 24 experimental units there was no germination, or the oldest plant died shortly after emergence. Frequency of missing data was not significantly affected by soil treatment $\left(\chi^{2}\right.$ $=0.75, \mathrm{df}=2, P=0.69)$, so these observations were excluded from analysis. However, including these observations yielded qualitatively similar results.

\section{Simulated Chaff Line Experiment}

Fifteen $11.5 \times 11.5 \mathrm{~cm}$ pots were filled with a $500 \mathrm{~g}$ soil, saturated with water, and seeded by placing $50 \mathrm{~A}$. tuberculatus seeds on the soil surface. Amaranthus tuberculatus was chosen as a test species because of its economic importance and high seed retention at maturity (Schwartz et al., 2016), making it a good candidate for control through chaff lining. Pots were either covered with $5 \mathrm{~g}$ finely ground hemp residue, $5 \mathrm{~g}$ finely ground maize residue, or left uncovered. This amount of residue is equivalent to $378 \mathrm{~g}$ $\mathrm{m}^{-2}$ of chaff. Each treatment was replicated five times. Pots were randomly arranged in a greenhouse with supplemental high-pressure sodium lights providing approximately $250 \mu \mathrm{mol}$ $\mathrm{m}^{-2} \mathrm{~s}^{-1}$ for $16 \mathrm{~h}$ each day. Pots were arranged in a completely randomized design. Pots were misted daily to maintain adequate moisture for germination. To facilitate germination, all pots were placed on a 12 V, 100-watt heat mat (Phytotronics, Earth City, MO, USA).

\section{Statistical Analyses}

The laboratory extract experiment was analyzed using mixedmodel analysis of variance (ANOVA), specifying treatment as a fixed effect and block as a random effect in order to test for an effect of treatment on the number of seeds that germinated per petri plate. Post-hoc comparisons were made using Tukey's HSD test. Data analysis was done using R version 4.0.5 (R Core Team, 2021) using the lme4 package (Bates et al., 2015).

Analysis of the growth in residue experiment was conducted on the response of each species individually. For each species, a hierarchical linear mixed-effect model was used to test for the effect of soil treatment on above-ground biomass. Soil treatment was modeled as a fixed effect, and block nested within run were modeled as random effects. To determine if there were species-specific biomass responses to soil treatment, a similar hierarchical linear mixed-effects modeling approach was used to test for interactions between soil treatment and species. For each plant species, length measurements were modeled as a hierarchical, repeated measures linear mixed-effect model. Plant nested within block nested within run were modeled as random effects, while soil, treatment, and time were modeled as fixed effects. Treatment means were separated by Tukey's test. To satisfy model assumptions, plant weight and plant length were square-root and $\log$ transformed, respectively. Mixed-model analysis was conducted in $\mathrm{R}$ using the lme4 package (Bates et al., 2015).

To evaluate differences between time-to-emergence in different soil treatments in the simulated chaff line experiment, the Kaplan-Meier survival functions and point-wise 95\% 


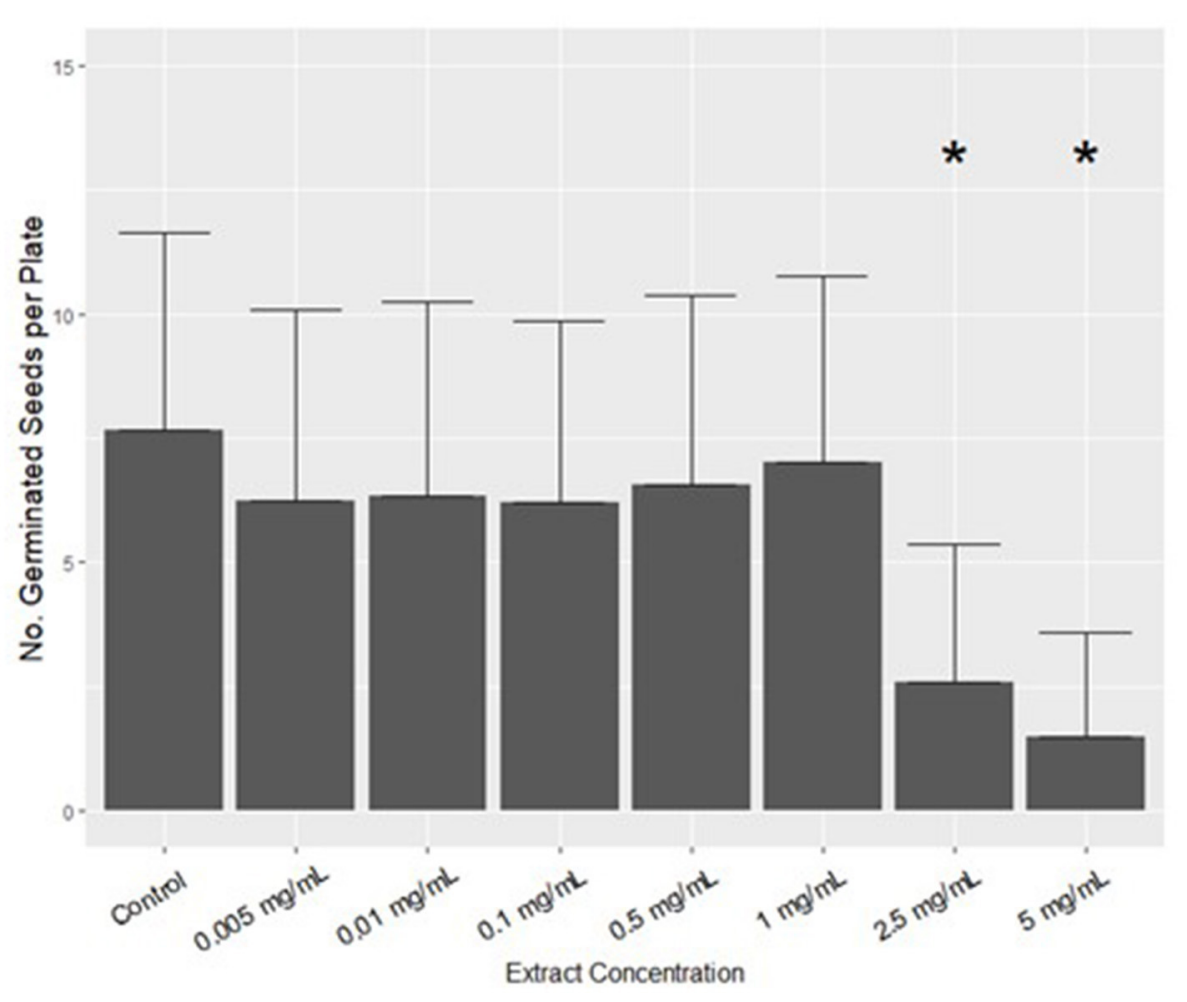

FIGURE 1 | The effect of Cannabis extract on the germination of Brassica napus after $115 \mathrm{~h}$ in growth-chamber conditions. Data are mean + standard deviation; standard deviation yields negative germination values and is therefore not presented. Groups with * are significantly different from the control, according to one way ANOVA followed by Tukey's test (alpha $=0.05$ ). Each treatment was replicated 20 times.

TABLE 1 | Repeated-measures F-tests for the effects of soil treatment, time, species, and all interactions on total plant length.

\begin{tabular}{lcccc}
\hline Source & df numerator df denominator & $\boldsymbol{F}$ & $\boldsymbol{P}$ \\
\hline Soil treatment & 2 & 124.1 & 51.862 & $<0.001$ \\
Time & 2 & 276.23 & $1037.09<0.001$ \\
Species & 5 & 122.89 & 130 & $<0.001$ \\
Soil treatment $\times$ time & 4 & 276.23 & 74.51 & $<0.001$ \\
Soil treatment $\times$ species & 10 & 122.62 & 3.87 & $<0.001$ \\
Time $\times$ species & 10 & 276.23 & 25.41 & $<0.001$ \\
Soil treatment $\times$ time $\times$ species & 20 & 276.23 & 10.77 & $<0.001$
\end{tabular}

Glycine max, Cannabis sativa, Triticum aestivum, Abutilon theophrasti, Setaria pumila, and Amaranthus tuberculatus were grown in soil, soil mixed with maize residue to $1 \%$ w:w, or soil mixed with hemp residue to $1 \%$ w:w over 28 days. Degrees of freedom are Satterthwaite approximations.

confidence intervals were estimated using the R package survival (Therneau, 2021). The log-rank test was used to test equality of distributions.

\section{Characterization of Plant Residues}

Analysis of terpenes and cannabinoids was performed at the Southern Illinois University Cannabis Science Center's analytical facilities. Homogenized hemp or maize was sifted using a $1.0 \mathrm{~mm}$ sieve to exclude large pieces of leaves, stem, or seeds. Then
$0.2 \mathrm{~g}$ of dried plant residue was sonicated in $10 \mathrm{~mL}$ of highperformance liquid chromatography (HPLC) grade methanol for $30 \mathrm{~min}$. The supernatant was passed through $0.45 \mu \mathrm{m}$ syringe filter and $1 \mathrm{~mL}$ was transferred to an autosampler vial for terpene analysis by gas chromatography with a flame ionization detector (GC-FID). Filtered supernatant was further diluted with HPLCgrade methanol 1:50 for cannabinoid analysis by HPLC with ultraviolet-visible (UV-vis) detection.

Terpenes were separated using an Agilent 6890 GC-FID (Agilent Technologies, Santa Clara, CA, USA) equipped with a Restek RXi-35Sil MS (Restek, Bellefonte, PA, USA.) column. The initial oven temperature was held at $50^{\circ} \mathrm{C}$ for $1 \mathrm{~min}$ and then ramped at $10^{\circ} \mathrm{C} \mathrm{min}^{-1}$ to $280^{\circ} \mathrm{C}$ where it was held for $6 \mathrm{~min}$. The injection volume was $5 \mu \mathrm{L}$. The inlet was $250^{\circ} \mathrm{C}$ and operated in 10:1 split mode. Column flowrate was $2.0 \mathrm{~mL} \min ^{-1}$. Nineteen terpenes [ $\alpha$-pinene, camphene, $\beta$ myrcene, (-)- $\beta$-pinene, $\delta$-3-carene, $\alpha$-terpinene, $d$-limonene, $\mathrm{p}$ cymene, ocimene, $\gamma$-terpinene, terpinolene, linalool, isopulegol, geraniol, $\beta$-caryophyllene, $\alpha$-humulene, nerolidol, guaiol, and $(-)$ - $\alpha$-bisabolol] were quantified using calibration standards prepared from Restek's Terpene Mix 1.

Cannabinoids were separated using an Agilent 1200 HPLC with a UV-vis photodiode array detection equipped with Kinetex C18 $(4.6 \times 50 \mathrm{~mm}$, particle size: $2.6 \mu \mathrm{m}$, pore size: $100 \AA)$ column (Phenomenex, Torrance, CA, USA) and detecting at $230 \mathrm{~nm}$. Mobile Phase A was Millipore 18 MOhm water (MilliporeSigma, 


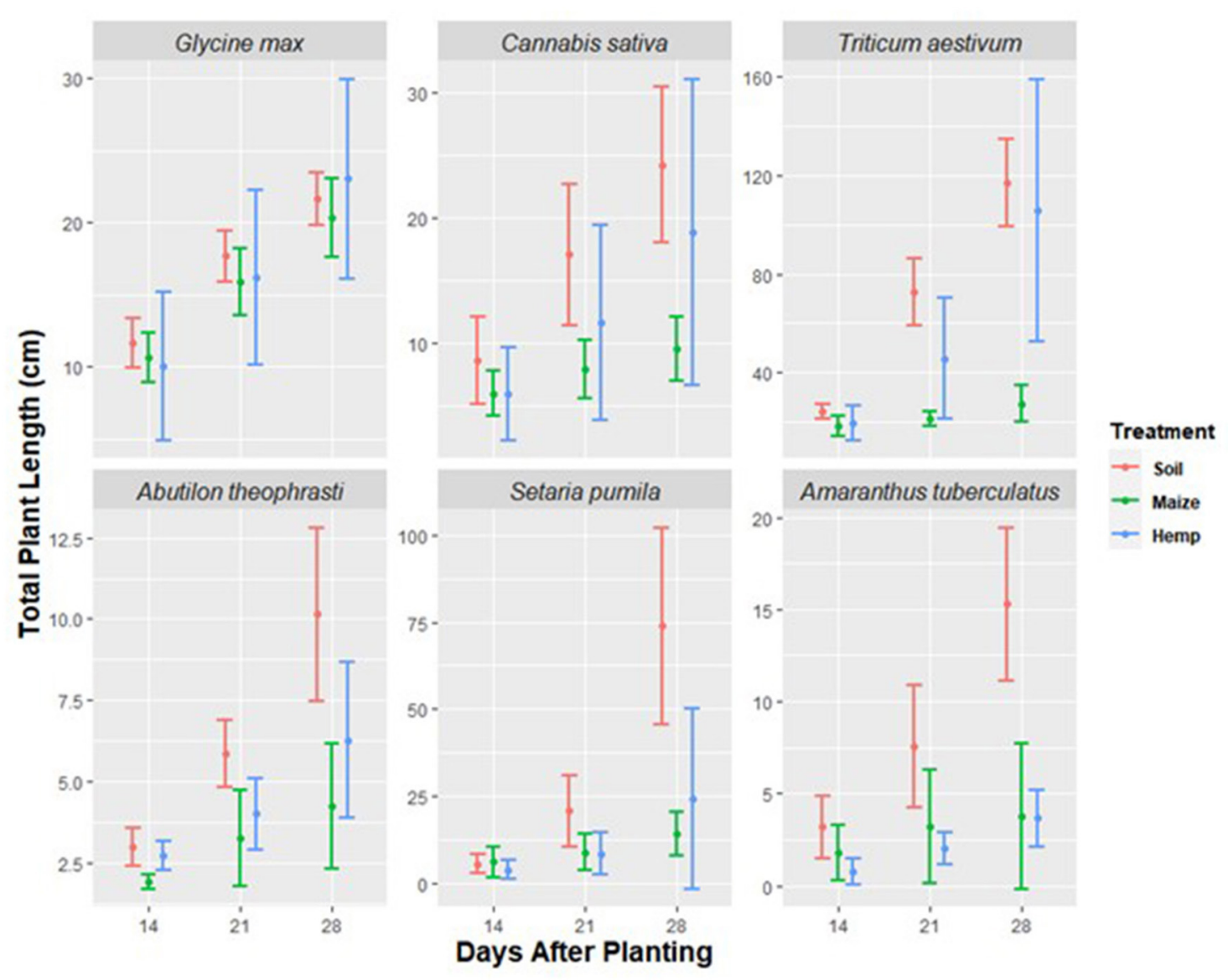

FIGURE 2 | Total plant length over time of six species (Glycine max, Cannabis sativa, Triticum aestivum, Abutilon theophrasti, Setaria pumila, and Amaranthus tuberculatus) grown in soil, soil mixed with maize residue to $1 \% \mathrm{w}: \mathrm{w}$ (maize), or soil mixed with hemp residue to $1 \% \mathrm{w}: \mathrm{w}$ (hemp). Data are mean \pm standard deviation. Experimental units with no germination were not related to soil treatment and were dropped from analysis. Thus, each species by soil treatment combination was replicated 10 times except for the following treatments: C. sativa + soil, C. sativa + maize, G. max + hemp, and A. theophrasti + hemp treatment combinations were replicated 9 times. C. sativa + hemp and $A$. theophrast + soil were replicated 8 times. $A$. theophrast + maize and $A$. tuberculatus + soil were replicated 7 times. $A$. tuberculatus + maize was replicated 5 times. A. tuberculatus + hemp was replicated 4 times.

Burlington, MA, USA) with $0.1 \%$ formic acid and Mobile Phase B was HPLC-grade methanol with $0.1 \%$ formic acid. The gradient elution program began at $60 \% \mathrm{~B}$ and reached $90 \% \mathrm{~B}$ at $12 \mathrm{~min}$ where it was held for $2 \mathrm{~min}$. The column oven set to $45^{\circ} \mathrm{C}$. Injection volume was $10 \mathrm{uL}$. Column flowrate was $1.0 \mathrm{~mL}$ $\mathrm{min}^{-1}$. THCa, THC, CBDa, CBD, and cannabinol (CBN) were quantitated using calibration standards prepared from certified reference materials purchased in $1 \mathrm{mg} \mathrm{mL}^{-1}$ concentrations (Cayman Chemical, Ann Arbor, MI, USA).

Analysis of carbon and nitrogen content of hemp and maize residue was performed by the Fermentation Science Institute at Southern Illinois University. Plant residue samples were finely ground, and five $10 \mathrm{mg}$ samples were weighed into $10 \times 12 \mathrm{~mm}$ tin capsules (CE Elantech, Lakewood, NJ, USA) and composition was determined using a Thermo Flash 2000 Elemental Analyzer (Thermo Fisher Scientific, Waltham, MA, USA).
TABLE 2 | F-tests for the effects of soil treatment, species, and soil treatment $x$ species on aboveground biomass for six species (Glycine max, Cannabis sativa, Triticum aestivum, Abutilon theophrasti, Setaria pumila, and Amaranthus tuberculatus) grown in soil, soil mixed with maize residue to $1 \% \mathrm{w}: \mathrm{w}$, or soil mixed with hemp residue to $1 \% \mathrm{w}: \mathrm{w}$.

\begin{tabular}{lcccc}
\hline Source & df numerator & df denominator & $\boldsymbol{F}$ & $\boldsymbol{P}$ \\
\hline Soil treatment & 2 & 129 & 82.02 & $<0.001$ \\
Species & 5 & 129.09 & 59.32 & $<0.001$ \\
Soil treatment $\times$ species & 10 & 129.03 & 2.89 & 0.0027
\end{tabular}

Degrees of freedom are Satterthwaite approximations.

\section{RESULTS}

The extract experiment showed a significant $\left[F_{(7,151)}=11.246\right.$, $P<0.001]$ effect of hemp extract on germination. Tukey's 

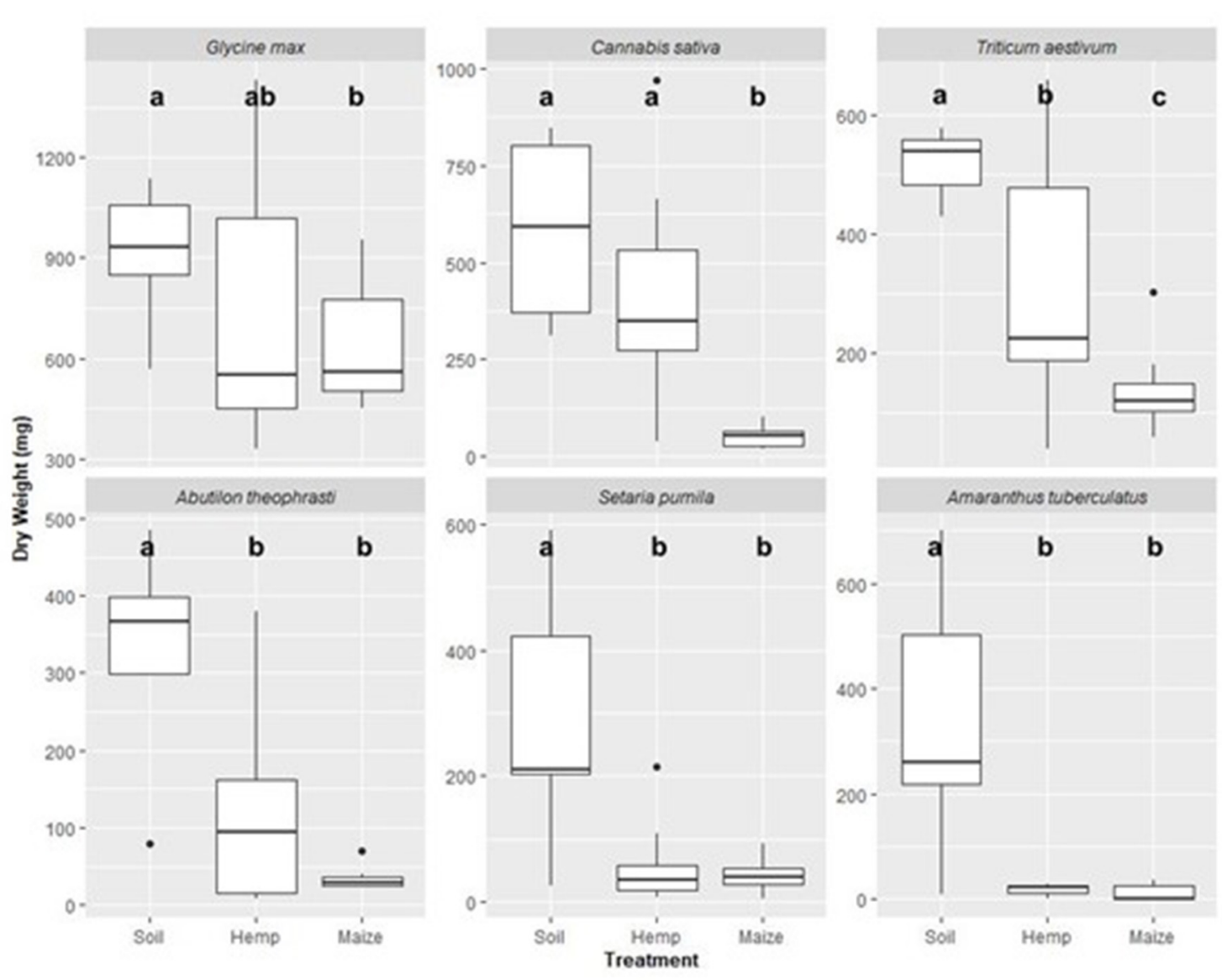

FIGURE 3 | Final, above-ground dry weight for six species (Glycine max, Cannabis sativa, Triticum aestivum, Abutilon theophrasti, Setaria pumila, and Amaranthus tuberculatus) grown in soil, soil mixed with maize residue to $1 \% \mathrm{w}$ :w (maize), or soil mixed with hemp residue to $1 \%$ w:w (hemp). Within a tested species, means sharing the same letter are not significantly different (Mixed-model ANOVA followed by Tukey's test, alpha $=0.05$ ). Experimental units with no germination were not related to soil treatment and were dropped from analysis. Thus, each treatment combination was replicated 10 times except for the following treatment combinations: C. sativa + soil, C. sativa + maize, G. max + hemp, and A. theophrasti + hemp treatment combinations were replicated 9 times. $C$. sativa + hemp and A. theophrasti + soil were replicated 8 times. $A$. theophrasti + maize and $A$. tuberculatus + soil were replicated 7 times. $A$. tuberculatus + maize was replicated 5 times. $A$. tuberculatus + hemp was replicated 4 times.

post-hoc test showed that 2.5 and $5 \mathrm{mg} \mathrm{mL}^{-1}$ treatments were effective in reducing germination of $B$. napus. However, assayed concentrations $<2.5 \mathrm{mg} \mathrm{mL}^{-1}$ did not significantly reduce germination. Compared to the control, the $5 \mathrm{mg} \mathrm{mL}^{-1}$ treatment reduced the average number of germinating seeds per plate by $80 \%$, from 7.65 to 1.5 seeds (Figure 1).

In the growth in residue experiment, time, treatment, species, and all second and third order interactions significantly affected the plant length (Table 1). Significant treatment $\times$ species and treatment $\times$ species $\times$ time interactions indicate the tested residues differentially affected plant growth depending on the species. In comparison to the soil treatment, plant length and above-ground dry weight could be reduced by the soil + hemp treatment. However, the reductions in length or weight due to hemp residue were never greater than reductions due to maize residue. Both maize and hemp residue treatments could reduce plant length, but the size of the effect depended on time and test species (Figure 2). Within a species, plant length was similar across soil treatments 14 days after planting. Twenty-eight days after planting, G. max length was not significantly affected by soil treatment. However, maize or hemp residue reduced estimated marginal mean $A$. tuberculatus height 28 days after planting from 13.9 to $3.8 \mathrm{~cm}$ and $2.1 \mathrm{~cm}$, representing a 73 and $85 \%$ decrease, respectively.

Final, above-ground biomass accumulation depended on the species sown, soil treatment, and the interaction between soil treatment and species (Table 2). Incorporated hemp residue reduced above-ground biomass in a species-specific manner. For example, in comparison to the soil treatment, the soil + hemp treatment reduced mean A. tuberculatus biomass from 274 to $10 \mathrm{mg}$, which represents a $96 \%$ decrease. However, the soil + hemp residue treatment did not significantly reduce G. max or C. sativa biomass (Figure 3). While incorporated hemp growth could effectively reduce biomass of weeds, 
soil + hemp never reduced biomass more than the soil + maize treatment.

The chaff line experiment showed that hemp residue reduced germination of $A$. tuberculatus in contrast to soil and maize residue treatments. The overall log-rank test was highly significant $\left[\chi_{(2)}^{2}=97.8, P<0.001\right]$ and Bonferroni-adjusted log-rank comparisons show that all groups are significantly different from one another (Figure 4). At the end of the chaff line experiment, fewer seeds germinated in the hemp treatment than in maize or soil treatments (hemp $=19 \%$, maize $=33 \%$, soil $=60 \%$ ). Of the seeds that did germinate, the mean germination time was longest in the hemp residue treatment (mean $=18.2$ days $\mathrm{SD}=6.8$ ) followed by soil (mean $=10.5$ days, $\mathrm{SD}=5.5$ ) and maize residue treatments (mean $=6.7$ days, $\mathrm{SD}=6.8$ ) (Figure 4 ).

Maize residue did not contain quantifiable levels of tested terpenes or cannabinoids. Hemp residue contained both terpenes and cannabinoids. CBDa was the most prevalent cannabinoid in hemp residue ( $16 \%$ dry weight), and eight terpenes tested were present in quantifiable amounts (Tables 3, 4). Of the quantified terpenes, $\beta$-caryophyllene was the most abundant. Hemp and maize residues also differed substantially in their carbon and nitrogen contents (Table 5). Hemp used in the present study had a relatively narrow carbon to nitrogen $(\mathrm{C}: \mathrm{N})$ ratio compared to maize at ratios of 14 and $108 \mathrm{C}: \mathrm{N}$, respectively.

\section{DISCUSSION}

The hypothesized role of hemp secondary metabolites in chemical ecology dates to at least 1970 (Haney and Bazzaz, 1970), yet, the effects of whole hemp residue or mixtures containing cannabinoids have not been tested in semi-realistic conditions. The present study shows that a complex mixture of hempderived phytochemicals inhibits germination of the bioindicator B. napus. Furthermore, the chaff line experiment demonstrates that hemp residue on the soil surface can reduce and delay emergence of a troublesome agricultural weed, A. tuberculatus, in comparison to maize and soil controls under greenhouse conditions. Reduced, delayed germination of A. tuberculatus caused by hemp residue suggests that chaff lining shows promise as a harvest weed seed control method if cannabinoid-producing grain hemp is incorporated into agricultural systems. While hemp-derived phytochemicals and whole hemp residue inhibit germination, incorporated residue was not effective in reducing above-ground biomass in comparison to a maize residue control.

While the results of the laboratory bioassay show extracted chemicals from hemp inhibit germination, this experiment does not demonstrate which components are responsible. However, there are likely additive and interactive effects of multiple components. Terpenes present in hemp can inhibit seed germination (De Martino et al., 2010), and cannabinoids are known to be phytotoxic in vitro (Sirikantaramas et al., 2005). However, understanding the effects of complex mixtures are needed to fully understand any effects hemp may have on other plants in field conditions (Duke, 2015). While examining components individually, and then in increasingly complex combinations can tease apart interactive effects, the large number

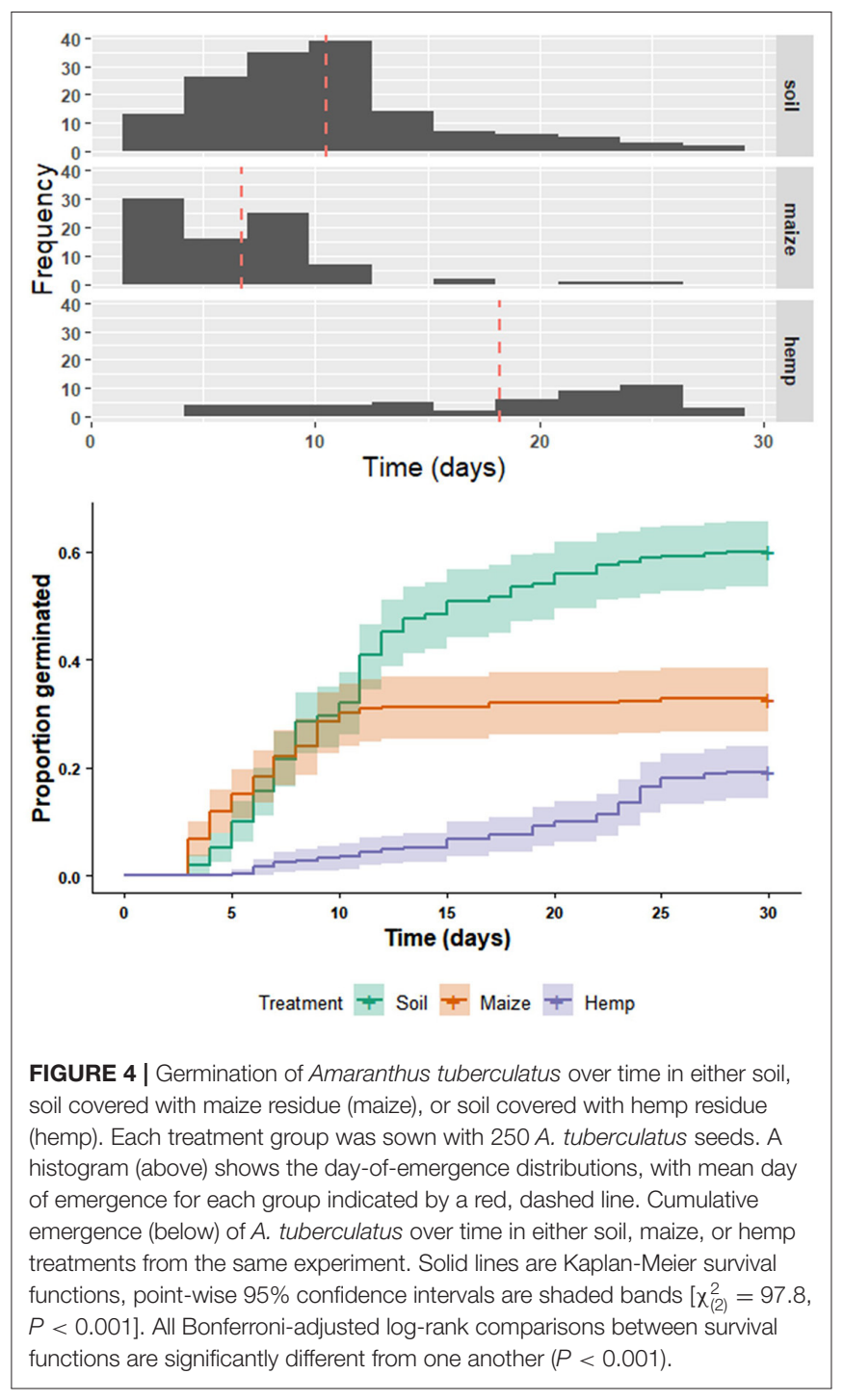

of chemicals in question made this logistically infeasible. More importantly, plants in nature encounter complex mixtures of chemicals simultaneously. Therefore, this study took a holistic approach and examined a crude extract and whole plant residue. Future work using isolated compounds in full factorial assays could be used to identify main effects and interactions. Knowledge of these phytotoxic effects could be used by breeders seeking to develop weed-suppressive hemp varieties, as well as chemists developing novel herbicide formulations.

When incorporated into the soil, hemp residue did not suppress the growth of weeds more than the maize treatment, making it unlikely that any potential allelopathy of incorporated hemp residue will be an effective weed-management practice. Intriguingly, sensitivity to residue type was species specific, highlighting the potential for residue management practices which favor crops over weed species. In accordance with previous research, addition of carbon-rich plant residue reduced the growth of the nitrophilous weeds A. theophrasti, A. 
tuberculatus, and S. pumila, hypothetically through reduced nitrogen availability (Blumenthal et al., 2003; Averett et al., 2004). Generally, addition of hemp residue reduced weed biomass as effectively as maize residue. For crop species, however, addition of hemp residue was less deleterious than addition of maize residue (Figure 2).

Hemp residue on the soil surface reduced and delayed the germination of $A$. tuberculatus, demonstrating the potential for chaff lining after hemp crops. Considered with the laboratory bioassay, it seems likely that terpenes, cannabinoids, or their combination are responsible for the decreased germination in the chaff line experiment. Ground maize residue has a similar consistency to hemp residue but differs in terpene and cannabinoid content and was intended to separate physical effects from phytotoxicity of hemp metabolites. However, this does not conclusively demonstrate the role of terpenes and cannabinoids in the simulated chaff line experiment. It is possible that maize and hemp residues have slightly different physical properties which could be affecting germination. To definitively determine whether terpenes, cannabinoids, or their combination in hemp residue are responsible for the inhibition in the chaff line experiment, further work is needed. Generation of near-isogenic lines differing in biochemical traits could be used to determine which hemp metabolites are potential allelochemicals. Regardless of the mechanism, hemp residue on the soil surface effectively delayed and reduced the germination of weed seeds in greenhouse conditions, suggesting that chaff lining hemp residue should be explored further as a weed management strategy.
These findings contrast with Walsh et al. (2021) which found that substantially more residue was required to suppress emergence of Lolium rigidum than was needed to suppress

TABLE 4 | Cannabidiol (CBD), Cannabidiolic acid (CBDa), cannabinol (CBN), $\Delta$ 9-tetrahydrocannabinol (THC), and tetrahydrocannabinolic acid (THCa) of hemp and maize residue used in experiments.

\begin{tabular}{lcc}
\hline & \multicolumn{2}{c}{ Species } \\
\cline { 2 - 3 } Cannabinoid & Hemp & Maize \\
\hline CBD & $0.91 \pm 0.01$ & $N^{a}$ \\
CBDa & $16.2 \pm 0.06$ & $N D$ \\
CBN & $0.21 \pm 0.01$ & $N D$ \\
THC & $0.104 \pm 0.009$ & $N D$ \\
THCa & $0.513 \pm 0.003$ & $N D$ \\
\hline
\end{tabular}

Data are percent dry weight and 95\% confidence intervals from 3 replicate injections. ${ }^{a} \mathrm{ND}$, not detected.

TABLE 5 | Carbon, nitrogen, and carbon:nitrogen (C:N) ratios of hemp and maize tissues used.

\begin{tabular}{lcc}
\hline & Hemp & Maize \\
\hline Carbon & $48.28 \pm 0.19 \%$ & $46.89 \pm 0.057 \%$ \\
Nitrogen & $3.46 \pm 0.059 \%$ & $0.44 \pm 0.19 \%$ \\
C:N & 13.98 & 107.8 \\
\hline
\end{tabular}

Data are mean and standard deviation $(n=3)$.

TABLE 3 | Analysis of terpenes tested in maize and hemp residues as determined by gas chromatography with a flame ionization detector.

\begin{tabular}{|c|c|c|c|c|c|c|c|c|}
\hline \multirow[b]{2}{*}{ Terpene } & \multicolumn{2}{|c|}{$\operatorname{LOD}^{a}$} & \multicolumn{2}{|c|}{$\mathrm{LOQ}^{\mathrm{b}}$} & \multicolumn{2}{|c|}{ Maize } & \multicolumn{2}{|c|}{ Hemp } \\
\hline & $(\mu \mathrm{g} / \mathrm{mL})$ & $(\mu \mathrm{g} / \mathrm{g})$ & $(\mu \mathrm{g} / \mathrm{mL})$ & $(\mu g / g)$ & $(\mu \mathrm{g} / \mathrm{g})$ & $\mathrm{Cl}^{\mathrm{C}}(95 \%)$ & $(\mu \mathrm{g} / \mathrm{g})$ & Cl $(95 \%)$ \\
\hline$\alpha$-pinene & 0.216 & 10.8 & 0.654 & 32.7 & $\mathrm{ND}^{\mathrm{d}}$ & - & $<\mathrm{LOQ}$ & - \\
\hline camphene & 0.306 & 15.3 & 0.926 & 46.3 & ND & - & ND & - \\
\hline$\beta$-myrcene & 0.175 & 8.7 & 0.529 & 26.4 & ND & - & 78.6 & 2.9 \\
\hline$(-)-\beta$-pinene & 0.214 & 10.7 & 0.649 & 32.4 & ND & - & 1025.6 & 46.7 \\
\hline §-3-carene & 0.378 & 18.9 & 1.145 & 57.2 & ND & - & ND & - \\
\hline$\alpha$-terpinene & 0.253 & 12.6 & 0.766 & 38.3 & ND & - & ND & - \\
\hline d-limonene & 0.126 & 6.3 & 0.38 & 19 & ND & - & 232.3 & 9.6 \\
\hline p-cymene & 0.116 & 5.8 & 0.343 & 17.6 & $<\mathrm{LOQ}$ & - & $<L O Q$ & - \\
\hline ocimene & 0.103 & 5.1 & 0.311 & 15.5 & ND & - & 152.4 & 6.4 \\
\hline$\gamma$-terpinene & 0.207 & 10.4 & 0.628 & 31.4 & ND & - & ND & - \\
\hline terpinolene & 0.241 & 12 & 0.73 & 36.5 & ND & - & ND & - \\
\hline linalool & 0.27 & 13.5 & 0.818 & 40.9 & ND & - & $<\mathrm{LOQ}$ & - \\
\hline isopulegol & 0.168 & 8.38 & 0.509 & 25.4 & ND & - & ND & - \\
\hline geraniol & 1.514 & 75.7 & 4.588 & 229 & ND & - & ND & - \\
\hline$\beta$-caryophyllene & 0.274 & 13.7 & 0.831 & 41.6 & ND & - & 1286.2 & 41.3 \\
\hline$\alpha$-humulene & 0.885 & 44.2 & 2.681 & 134 & ND & - & 487.7 & 20.8 \\
\hline nerolidol & 0.189 & 9.4 & 0.571 & 28.6 & ND & - & $<\mathrm{LOQ}$ & - \\
\hline guaiol & 0.038 & 1.9 & 0.115 & 5.75 & ND & - & 599.1 & 18.1 \\
\hline (-)- $\alpha$-bisabolol & 0.075 & 3.75 & 0.226 & 11.3 & ND & - & 464.4 & 13.6 \\
\hline
\end{tabular}

${ }^{a} L O D$, limit of detection. ${ }^{b} L O Q$, limit of quantification. ${ }^{c} \mathrm{Cl}$, confidence interval, ${ }^{d} \mathrm{ND}$, not detected. 
A. tuberculatus emergence in the present study. This disparity suggests that there may be species and residue specific responses to burial in chaff lines, which should be explored further. Susceptibility of $A$. tuberculatus to either type of residue tested may make it a good candidate for control through chaff lining. Furthermore, incorporation of hemp into crop rotation using chaff lining may be an especially effective integrated weed management tactic for A.tuberculatus control, an economically damaging weed with limited control options (Tranel et al., 2011).

Differences in C:N ratios may be obscuring potential allelopathy in the growth in residue experiment. We compared ground maize residue to ground hemp residue because of their similar consistency. However, subsequent testing showed large differences in carbon and nitrogen content. Maize and hemp residue in the present study had C:N ratios of 108 and 14, respectively. Based on C:N ratios, addition of maize residue to soil is expected to result in nitrogen immobilization, while addition of hemp residue is expected to result in nitrogen mineralization. Despite having a narrow C:N ratio, hemp residue significantly reduced growth of weed when incorporated into the soil, suggesting that allelopathic effects are possible. However, potential allelopathy of incorporated hemp residue needs further investigation and future work should incorporate measurements of plant available nitrogen over time.

The strong inhibition of weeds by either incorporated maize or hemp residue underscores the potential to integrate crop, nutrient, and weed management considerations. Incorporated hemp and maize residues both effectively suppressed the growth of tested weed species. However, crop species were generally less sensitive than weeds to addition of either residue. Differing responses between cultivated plants and weed pests can be exploited to suppress weeds while maintaining acceptable crop growth (Ryan et al., 2010). Differential tolerances to potential allelochemicals or nitrogen immobilization may be mediated by traits such as seed size and nitrogen requirements. Large-seeded species generally have greater tolerance to phytotoxins (Liebman and Sundberg, 2006), and low nitrogen availability can effectively reduce performance of weeds while maintaining high soybean yield (Menalled et al., 2021).

The present study is a proof-of-concept of the potential of hemp residue to be used in an integrated weed management program, but further work is required to determine if hemp is

\section{REFERENCES}

Abrahim, D., Braguini, W. L., Kelmer-Bracht, A. M., and Ishii-Iwamoto, E. L. (2000). Effects of four monoterpenes on germination, primary root growth, and mitochondrial respiration of maize. J. Chem. Ecol. 26, 611-624. doi: 10.1023/A:1005467903297

Agnieszka, S., Magdalena, R., Jan, B., Katarzyna, W., Malgorzata, B., Krzysztof, H., et al. (2016). Phytotoxic effect of fiber hemp essential oil on germination of some weeds and crops. J. Essent. Oil Bear. Plants 19, 262-276. doi: 10.1080/0972060X.2015.1137236

Almberg, K. S., Turyk, M. E., Jones, R. M., Rankin, K., Freels, S., and Stayner, L. T. (2018). Atrazine contamination of drinking water and adverse birth outcomes in community water systems with elevated atrazine in Ohio, 2006-2008. Int. J. Environ. Res. Public Health 15, 1-14. doi: 10.3390/ijerph15091889 allelopathic in field conditions. Future studies should use more varieties to determine if potential allelopathy differs between hemp cultivars. Furthermore, the spatio-temporal fate of hemp secondary metabolites in an agroecosystem after biosynthesis is largely unknown. Monitoring the abundance of terpenes and cannabinoids over time will clarify if hemp is allelopathic in field conditions. A full view of hemp's chemical ecology will need to incorporate the interactions with microbes. The present study used pasteurized soil to avoid effects of pathogens and clearly test direct phytotoxicity of hemp residue. However, many plants interact with microbes through chemical exudates. Accordingly the soil microbiomes associated with hemp is known to vary by chemotype (Winston et al., 2014). Plant-growthpromoting microbes can promote nutrient availability, plant health, and enhance plant performance (Kloepper et al., 1980; Nihorimbere et al., 2011), and could hypothetically facilitate hemp growth. Alternatively, hemp exudates could also affect soil-microbial communities which in turn could negatively affect competing plants (Inderjit, 2005). Future work should investigate any role of microbes in hemp growth, competition, and potential allelopathy.

\section{DATA AVAILABILITY STATEMENT}

The datasets presented in this study can be found in online repositories. The names of the repository/repositories and accession number(s) can be found below: https:/github.com/ averyshikanai/Thesis-data.

\section{AUTHOR CONTRIBUTIONS}

Both authors listed have made a substantial, direct, and intellectual contribution to the work and approved it for publication.

\section{ACKNOWLEDGMENTS}

We thank John Miller, Austin Barron, and Brandon Marsden for their assistance conducting the experiments, and Nolan Shikanai for his help with data management. We thank Mary Kinsel of the Cannabis Science Center and Amanda Rothert of the Fermentation Science Institute for assistance with chemical analysis.

Averett, J. M., Klips, R. A., Nave, L. E., Frey, S. D., and Curtis, P. S. (2004). Effects of soil carbon amendment on nitrogen availability and plant growth in an experimental tallgrass prairie restoration. Restor. Ecol. 12, 568-574. doi: 10.1111/j.1061-2971.200 4.00284.x

Bates, D., Mächler, M., Bolker, B. M., and Walker, S. C. (2015). Fitting linear mixed-effects models using lme4. J. Stat. Softw. 67, 1-48. doi: 10.18637/jss.v0 67.i01

Bish, M. D., Farrell, S. T., Lerch, R. N., and Bradley, K. W. (2019). Dicamba losses to air after applications to soybean under stable and nonstable atmospheric conditions. J. Environ. Qual. 48, 1675-1682. doi: 10.2134/jeq201 9.05.0197

Blumenthal, D. M., Jordan, N. R., and Russelle, M. P. (2003). Soil carbon addition controls weeds and facilitates prairie restoration. Ecol. 
Appl. 13, 605-615. doi: 10.1890/1051-0761(2003)013[0605:SCACWA] 2.0.CO;2

Chen, F., Tholl, D., Bohlmann, J., and Pichersky, E. (2011). The family of terpene synthases in plants: a mid-size family of genes for specialized metabolism that is highly diversified throughout the kingdom. Plant J. 66, 212-229. doi: 10.1111/j.1365-313X.2011.04520.x

Davis, A. S. (2006). When does it make sense to target the weed seed bank? Weed Sci. 54, 558-565. doi: 10.1614/ws-05-058r.1

Davis, A. S., Hill, J. D., Chase, C. A., Johanns, A. M., and Liebman, M. (2012). Increasing cropping system diversity balances productivity, profitability and environmental health. PLoS ONE 7, e47149. doi: 10.1371/journal.pone. 0047149

De Martino, L., Mancini, E., De Almeida, L. F. R., and De Feo, V. (2010). The antigerminative activity of twenty-seven monoterpenes. Molecules 15, 6630-6637. doi: 10.3390/molecules 1 5096630

Duke, S. O. (2012). Why have no new herbicide modes of action appeared in recent years? Pest Manag. Sci. 68, 505-512. doi: 10.1002/ps.2333

Duke, S. O. (2015). Proving allelopathy in crop-weed interactions. Weed Sci. 63, 121-132. doi: 10.1614/WS-D-1300130.1

Fischedick, J. T., Hazekamp, A., Erkelens, T., Choi, Y. H., and Verpoorte, R. (2010). Metabolic fingerprinting of Cannabis sativa L., cannabinoids and terpenoids for chemotaxonomic and drug standardization purposes. Phytochemistry 71, 2058-2073. doi: 10.1016/j.phytochem.2010.10.001

Gallandt, E. R. (2006). How can we target the weed seedbank? Weed Sci. 54, 588-596. doi: 10.1614/ws-0 5-063r.1

Haney, A., and Bazzaz, F. A. (1970). "Some ecological implications of the distribution of hemp (Cannabis sativa L.) in the United States of America," in The Botany and Chemistry of Cannabis: Proceedings of a Conference Organized by the Institute for the Study of Drug Dependence at the Ciba Foundation, eds C. R. B. Joyce, S. H. Curry, and S. H. Curry (London: J. \& A. Churchill), 39-47.

Inderjit (2005). Soil microorganisms: an important determinant of allelopathic activity. Plant Soil 274, 227-236. doi: 10.1007/s1104-00 4-0159-x

Inderjit, Weston, L. A., and Duke, S. O. (2005). Challenges, achievements and opportunities in allelopathy research. J. Plant Interact. 1, 69-81. doi: 10.1080/17429140600622535

Jabran, K., Mahajan, G., Sardana, V., and Chauhan, B. S. (2015). Allelopathy for weed control in agricultural systems. Crop Prot. 72, 57-65. doi: 10.1016/j.cropro.2015.03.004

Kloepper, J. W., Schroth, M. N., and Miller, T. D. (1980). Effects of rhizosphere coloinization by plant growth-promoting rhizobacteria on potato plant development and yield. Phytopathology 70, 1078-1082.

Koitabashi, R., Suzuki, T., Kawazu, T., Sakai, A., Kuroiwa, H., and Kuroiwa, T. (1997). 1, 8-Cineole inhibits root growth and DNA synthesis in the root apical meristem of Brassica campestris L. J. Plant Res. 110, 1-6.

Köllner, T. G., Schnee, C., Gershenzon, J., and Degenhardt, J. (2004). The sesquiterpene hydrocarbons of maize (Zea mays) form five groups with distinct developmental and organ-specific distributions. Phytochemistry 65, 1895-1902. doi: 10.1016/j.phytochem.2004.05.021

Kruidhof, H. M., Bastiaans, L., and Kropff, M. J. (2009). Cover crop residue management for optimizing weed control. Plant Soil 318, 169-184. doi: 10.1007/s11104-008-9827-6

Liebman, M., and Dyck, E. (1993). Crop rotation and intercropping strategies for weed management. Ecol. Appl. 3, 92-122. doi: 10.2307/ 1941795

Liebman, M., and Sundberg, D. N. (2006). Seed mass affects the susceptibility of weed and crop species to phytotoxins extracted from red clover shoots. Weed Sci. 54, 340-345. doi: 10.1043/0043-1745(2006)54[340:SMATSO]2.0.CO;2

Livingston, S. J., Quilichini, T. D., Booth, J. K., Wong, D. C. J., Rensing, K. H., Laflamme-Yonkman, J., et al. (2020). Cannabis glandular trichomes alter morphology and metabolite content during flower maturation. Plant J. 101, 37-56. doi: 10.1111/tpj.14516
Menalled, U. D., Pethybridge, S. J., Pelzer, C. J., Smith, R. G., DiTommaso, A., and Ryan, M. R. (2021). High seeding rates and low soil nitrogen environments optimize weed suppression and profitability in organic no-till planted soybean. Front. Agron. 3, 678567. doi: 10.3389/fagro.2021.678567

Nihorimbere, V., Ongena, M., Smargiassi, M., and Thonart, P. (2011). Beneficial effect of the rhizosphere microbial community for plant growth and health. Biotechnol. Agron. Soc. Environ. 15, 327-337.

Pacifico, D., Miselli, F., Carboni, A., Moschella, A., and Mandolino, G. (2008). Time course of cannabinoid accumulation and chemotype development during the growth of Cannabis sativa L. Euphytica 160, 231-240. doi: 10.1007/s10681-007-9543-y

R Core Team (2021). R: A Language and Environment for Statistical Computing. R Foundation for Statistical Computing, Vienna. Available online at: https:// www.R-project.org/

Relyea, R. A. (2009). A cocktail of contaminants: how mixtures of pesticides at low concentrations affect aquatic communities. Oecologia 159, 363-376. doi: 10.1007/s00442-008-1213-9

Ryan, M. R., Smith, R. G., Mirsky, S. B., Mortensen, D. A., and Seidel, R. (2010). Management filters and species traits: weed community assembly in long-term organic and conventional systems. Weed Sci. 58, 265-277. doi: 10.1614/ws-d-09-00054.1

Sandler, L. N., and Gibson, K. A. (2019). A call for weed research in industrial hemp (Cannabis sativa L). Weed Res. 59, 255-259. doi: 10.1111/wre.12368

Schluttenhofer, C., and Yuan, L. (2017). Challenges towards revitalizing hemp: a multifaceted crop. Trends Plant Sci. 22, 917-927. doi: 10.1016/j.tplants.2017.08.004

Schwartz, L. M., Norsworthy, J. K., Young, B. G., Kevin, W., Kruger, G. R., Davis, V. M., et al. (2016). Tall waterhemp (Amaranthus tuberculatus) and Palmer amaranth (Amaranthus palmeri) seed production and retention at soybean maturity. Weed Technol. 30, 284-290. doi: 10.161 4/WT-D-1

Sirikantaramas, S., Taura, F., Tanaka, Y., Ishikawa, Y., Morimoto, S., and Shoyama, Y. (2005). Tetrahydrocannabinolic acid synthase, the enzyme controlling marijuana psychoactivity, is secreted into the storage cavity of the glandular trichomes. Plant Cell Physiol. 46, 1578-1582. doi: 10.1093/pc p/pcil66

Tabaglio, V., Marocco, A., and Schulz, M. (2013). Allelopathic cover crop of rye for integrated weed control in sustainable agroecosystems. Ital. J. Agron. 8, 35-40. doi: 10.4081/ija.2013.e5

Therneau, T. M. (2021). A Package for Survival Analysis in R. R package version 3.2-13. Mayo Clinic, Rochester, MN. Available online at: https://cran.r-project. org/package $=$ survival/survival.pdf

Toth, J. A., Stack, G. M., Cala, A. R., Carlson, C. H., Wilk, R. L., Crawford, J. L., et al. (2020). Development and validation of genetic markers for sex and cannabinoid chemotype in Cannabis sativa L. GCB Bioenergy 12, 213-222. doi: 10.1111/gcbb.12667

Tranel, P. J., Riggins, C. W., Bell, M. S., and Hager, A. G. (2011). Herbicide resistances in Amaranthus tuberculatus: a call for new options. J. Agric. Food Chem. 59, 5808-5812. doi: 10.1021/jf103797n

Walsh, M. J., Broster, J. C., Schwartz-Lazaro, L. M., Norsworthy, J. K., Davis, A. S., Tidemann, B. D., et al. (2018). Opportunities and challenges for harvest weed seed control in global cropping systems. Pest Manag. Sci. 74, 2235-2245. doi: 10.1002/ps.4802

Walsh, M. J., Rayner, A. E., Ruttledge, A., and Broster, J. C. (2021). Influence of chaff and chaff lines on weed seed survival and seedling emergence in Australian cropping systems. Weed Technol. 35, 515-521. doi: 10.1017/wet.2020.142

Wang, M., Wang, Y. H., Avula, B., Radwan, M. M., Wanas, A. S., Van Antwerp, J., et al. (2016). Decarboxylation study of acidic cannabinoids: a novel approach using ultra-high-performance supercritical fluid chromatography/photodiode array-mass spectrometry. Cannabis Cannabinoid Res. 1, 262-271. doi: 10.1089/can.2016.0020

Westerman, P. R., Liebman, M., Menalled, F. D., Heggenstaller, A. H., Hartzler, R. G., and Dixon, P. M. (2005). Are many little hammers effective? Velvetleaf (Abutilon theophrasti) population dynamics in two- and four-year crop rotation systems. Weed Sci. 53, 382-392. doi: 10.1614/ws04-130r 
Winston, M. E., Hampton-Marcell, J., Zarraonaindia, I., Owens, S. M., Moreau, C. S., Gilbert, J. A., et al. (2014). Understanding cultivarspecificity and soil determinants of the Cannabis microbiome. PLoS ONE 9, e99641. doi: 10.1371/journal.pone.0099641

Conflict of Interest: The authors declare that the research was conducted in the absence of any commercial or financial relationships that could be construed as a potential conflict of interest.

Publisher's Note: All claims expressed in this article are solely those of the authors and do not necessarily represent those of their affiliated organizations, or those of the publisher, the editors and the reviewers. Any product that may be evaluated in this article, or claim that may be made by its manufacturer, is not guaranteed or endorsed by the publisher.

Copyright (๑) 2022 Shikanai and Gage. This is an open-access article distributed under the terms of the Creative Commons Attribution License (CC BY). The use, distribution or reproduction in other forums is permitted, provided the original author(s) and the copyright owner(s) are credited and that the original publication in this journal is cited, in accordance with accepted academic practice. No use, distribution or reproduction is permitted which does not comply with these terms. 